\title{
Endosulfan sulphate interferes with reproduction, embryonic development and sex differentiation in Daphnia magna
}

\author{
P. Palma ${ }^{\text {a,c,* }}$, V.L. Palma ${ }^{\text {a }}$, R.M. Fernandes ${ }^{\text {a }}$, A.M.V.M. Soares ${ }^{\text {b }}$, I.R. Barbosa ${ }^{c}$ \\ a Departamento de Ciências do Ambiente, Escola Superior Agrária de Beja, Beja 7800-295, Portugal \\ b CESAM \& Departamento de Biologia da Universidade de Aveiro, Aveiro 3810-193, Portugal

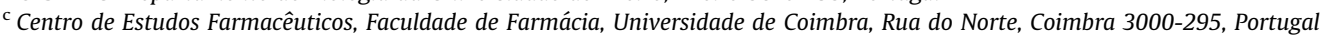

\section{A R T I C L E I N F O}

\section{Article history:}

Received 3 February 2008

Received in revised form

23 April 2008

Accepted 26 April 2008

\section{Keywords:}

Daphnia magna

Endosulfan sulphate

Embryo development

Reproduction

Moulting frequency

Sex ratio

\begin{abstract}
A B S T R A C T
Endosulfan sulphate is the transformation product of endosulfan and it is the most frequent form of surface water contamination with endosulfan. The aim of this study was to evaluate the possible effects promoted by endosulfan sulphate in changes on the life cycle, embryo development and sex differentiation of Daphnia magna. The endpoints used were moulting frequency, fecundity, growth, developmentally abnormalities and sexual differentiation. The nominal concentrations of endosulfan sulphate tested ranged from 9.2 to $458.7 \mu \mathrm{g} \mathrm{L}^{-1}$. Endosulfan sulphate promoted a significant decrease of the offspring number in all concentrations. Results showed a reduction of the size of females, together with a decrease in moulting frequency. Furthermore, an increase in embryo deformities was observed at all concentrations tested. Above a concentration of $91.7 \mu \mathrm{g} \mathrm{L}^{-1}$ there was an increased production of males. The results suggest that endosulfan sulphate interferes with the life cycle and sex determination of the crustacean D. magna.
\end{abstract}

(c) 2008 Elsevier Inc. All rights reserved.

\section{Introduction}

Despite the restricted use of organochlorine pesticides, due to their high persistence in different environmental ecosystems, some organochlorine cyclodiene insecticides are still being used, namely endosulfan. This pesticide is commonly used, due to its relatively low mammalian toxicity and short persistence in the environment, as compared to many other organochlorine compounds. Nevertheless, it is very toxic to fish and other aquatic species (Nowak et al., 1995; DeFur, 2004). Endosulfan is extensively used for the control of plagues in the crops of tomato, beets and cereals all over the world. Its mode of action in targeting insect pests is by stimulation of the central nervous system through inhibition of the GABA ( $\gamma$-aminobutyric acid) receptor (Klaassen, 2001).

Endosulfan is an insecticide, consisting of a mixture of isomers $\alpha$-endosulfan and $\beta$-endosulfan in a ratio of $2: 1-7: 3$ (Herrmann, 2003). Endosulfan sulphate is the transformation product of both isomers (Wan et al., 2004). In water, the half-life of endosulfan is about 1-3 months, while the half-life of endosulfan sulphate can be between 2 and 6 years, depending on the environmental conditions (Herrmann, 2003). This fact is one of the reasons why this compound (endosulfan sulphate) is the most frequent form

\footnotetext{
* Corresponding author at: Departamento de Ciências do Ambiente, Escola Superior Agrária de Beja, Beja 7800-295, Portugal. Fax: +351 284388207.

E-mail address: ppalma@esab.ipbeja.pt (P. Palma).
}

detected in surface water (Shivaramaiah et al., 2005), as is confirmed by several data sets (Pfeuffer and Rand, 2004; Leong et al., 2007; Palma et al., 2007; unpublished). Endosulfan sulphate induces an acute toxicity similar to endosulfan in representative freshwater invertebrates; this action was already well documented (Barry et al., 1995; Lemke, 1980; Sunderam et al., 1994; Wan et al., 2004; Palma et al., 2007, submitted). There are several reports mentioning the chronic toxicity promoted by endosulfan. Studies reported that endosulfan interferes with reproduction rate, moulting and development in both freshwater (FernandezCasalderrey et al., 1993; Foersom et al., 2001) and marine (Wirth et al., 2001) crustaceans. However, data gaps exist with respect to the impacts of sublethal concentrations of endosulfan sulphate in crustaceans at various levels, namely, changes in the life cycle, embryo development and alterations in the endogenous endocrine system of these species. Some reports indicate that both compounds (endosulfan and endosulfan sulphate) have oestrogenic activity in human oestrogen-sensitive cells (Soto et al., 1995), and that endosulfan antagonises the action of androgens (LeBlanc et al., 1997; McKinlay et al., 2007). Nevertheless, few data exist on the endocrine effects promoted by endosulfan sulphate on invertebrate in vivo bioassays. All these results are essential to define and understand the real aquatic ecological impact of endosulfan sulphate, as it is the most frequent and persistent transformation form of the pesticide endosulfan in the aquatic ecosystem. Besides, these results are also important for the complete evaluation of endosulfan toxicological profile. 
The aim of this study was first to establish the effect of endosulfan sulphate on the life cycle of Daphnia magna and to determine the relationship between the production of offspring, growth and moulting process. Second, it was to evaluate if endosulfan sulphate acts as an embryo-toxic compound and, finally, to assess the effect of this compound on the sex determination of $D$. magna.

The endpoints used were growth, moulting frequency, fecundity (number of viable offspring per female), embryo toxicity and sex determination.

\section{Materials and methods}

\subsection{Chemicals}

Endosulfan sulphate PESTANAL ${ }^{\circledR}\left(\mathrm{C}_{9} \mathrm{H}_{6} \mathrm{Cl}_{6} \mathrm{O}_{4} \mathrm{~S}\right.$; CAS No. 1031-07-8; 97.7\% purity) was obtained from Riedel-de-Häen Laborchemikalien GmbH. Dimethyl sulphoxide (DMSO) obtained from Merk ${ }^{\mathbb{B}}$ ( $>99 \%$ purity) was used as a solvent, at a maximum concentration of $0.01 \%(\mathrm{v} / \mathrm{v})$ (Barbosa et al., 2003). All working stock solutions were made immediately prior to the tests. The solvent control was included in all tests.

\subsection{Animal cultures}

Daphnids were obtained from continuous cultures maintained in the laboratory, in $800 \mathrm{ml}$ of ASTM hard water (ASTM, 1998), enriched with the organic additive Marine "25" (Pann Britannica Industries Ltd., Waltham Abbey, UK), an extract from the algae Ascophyllum nodosum (Baird et al., 1989), at a concentration of $4.0 \mathrm{mll}^{-1}$. The cultured medium was renewed three times per week. Animal density was 15 animals per $800 \mathrm{~mL}$. Daphnids were fed with algae (Pseudokirchneriella subcapitata) with a density of $3.0 \times 10^{5}$ cells ml $^{-1}$ Daphnia $^{-1}$ (an equivalent carbon content of $2.65 \mathrm{mg} \mathrm{Cml}^{-1}$ ) maintained with a photoperiod of $16 \mathrm{~h}$ light: $8 \mathrm{~h}$ dark, at a light intensity of $100-1000 \mathrm{Lx}$ and in the temperature of $20 \pm 1{ }^{\circ} \mathrm{C}$. Experimental conditions were maintained so as not to induce male neonate production.

The chronic assays were initiated with the 3rd brood of neonates ( $\leqslant 24 \mathrm{~h}$ old $)$ from a single clone derived from a healthy parent stock culture.

D. magna eggs were obtained from females of the laboratory cultures; only the eggs from the third to fifth broods were used in direct embryo exposure test.

\subsection{Chronic reproduction test: maternal exposure to endosulfan sulphate}

To assess the effects of endosulfan sulphate on the reproduction of daphnids, tests were conducted in accordance with the "Daphnia magna reproduction test" provided by test guideline 211 of the Organization for Economic Cooperation and Development (OCDE, 1998). Endosulfan sulphate concentrations, used in the reproduction bioassay, were determined from the results of $48 \mathrm{~h} \mathrm{LC}_{50}\left(\mu \mathrm{g} \mathrm{L}^{-1}\right)$ obtained in a previous study (Palma et al., 2007, article submitted).

Daphnids, less then $24 \mathrm{~h}$ old, were exposed to the control (ASTM hard water) control solvent (ASTM+DMSO), with a nominal concentration of $0.01 \%(\mathrm{v} / \mathrm{v})$ and to the nominal concentrations of endosulfan sulphate $(9.2,45.8,91.7,229.3$, $458.7 \mu \mathrm{g} \mathrm{L}^{-1}$ ). Ten replicates per treatment group were used with one daphnia per glass jar, filled with $50 \mathrm{ml}$ of test concentration. Daphnids were fed daily with $P$. subcapitata with a density of $3.0 \times 10^{5}$ cells ml $^{-1}$ Daphnia $^{-1}$. Test solutions were renewed three times a week. Test solutions were also enriched with organic additive. All experiments were conducted in a chamber with constant temperature $\left(20 \pm 1^{\circ} \mathrm{C}\right)$ and a photoperiod of $16 \mathrm{~h}$ light: $8 \mathrm{~h}$ dark. During the experiments, temperature, $\mathrm{pH}$, electrical conductivity and dissolved oxygen were monitored weekly. Daphnid maturation was assessed by the moulting frequency and by the time required for deposition of the first brood of embryos into the brood chamber. The moult frequency of individual daphnids was assessed daily and it was determined by the total number of moults, during the test. Reproduction rate was estimated by the total number of viable offspring produced by each female. Embryonic development was assessed by microscopical examination of individual offspring produced by each female, verifying the existence of development abnormalities.

\subsection{Sex differentiation}

To assess the effects of endosulfan sulphate on daphnids sex differentiation, tests (two groups of experiments) were conducted in accordance with the "Daphnia magna reproduction test" provided by test guideline 211 of the Organization for Economic Cooperation and Development (OCDE, 1998). The nominal concentrations of control, control solvent and endosulfan sulphate, as well as the experiments conditions were mentioned above. Daphnids began releasing offspring on approximately day 8, then offspring production was assessed daily and individual offspring was evaluated microscopically to establish the sex of neonate, which was determined based on the length of the first antennae (Olmstead and LeBlanc, 2000).

\subsection{Direct embryo exposure to endosulfan sulphate}

Just after the release of the third brood, females were isolated from culture and observed until the passage of the new eggs from the ovaries to the brood chamber This event was considered to represent time zero of eggs development. Eight hours after time zero, females were placed under a dissecting microscope and eggs were removed by introducing a small pipette with ASTM hard water in the brood chamber to create a slow flow, pushing the eggs to the microscope slide (Sobral et al., 2001). After being washed, eggs were placed in individual wells of tissue culture plates either with $1 \mathrm{ml}$ of control (ASTM), control solvent with a concentration of $0.01 \%(\mathrm{v} / \mathrm{v})$ (ASTM+DMSO) or with endosulfan sulphate, at the desired nominal concentration $\left(9.2,45.8,91.7,229.3,458.7 \mu \mathrm{g} \mathrm{L}^{-1}\right)$, with 12 replicates per concentration. Embryos were incubated at a constant temperature $\left(20 \pm 1^{\circ} \mathrm{C}\right)$ with a photoperiod $16 \mathrm{~h}$ light: $8 \mathrm{~h}$ dark cycle. Embryo development was observed at 24,48 and $96 \mathrm{~h}$. The percentage of embryos that exhibited development abnormalities was determined when the development of the control eggs was completed. For the analysis of embryo toxicity we followed the six stages of embryonic development described by LeBlanc et al. (2000).

\subsection{Statistical analysis}

Data were checked for homogeneity of variance (Kolmogorov-Sminov test) (Sokal and Rohlf, 1995) and, when possible, subjected to one-way ANOVA. Data that did not satisfy the assumption for ANOVA were analysed non-parametrically using Kruskal-Wallis ANOVA by the Ranks test. Whenever significant differences were found $(p<0.05)$, a post-hoc Dunnett's test was used to compare treatments with the control with a $p$-value of 0.05 as the significant level (Zar, 1996). This analysis was performed using STATISTIC 6.0 Software ${ }^{\text {TM }}$ Inc., PA, USA (2001). Data with values ranging from 0 to 1 , such as sex ratio, were transformed using the arcsine square root transformation prior to statistical analysis. The effect of endosulfan sulphate on the production of male offspring of male sex was tested by logistic regression analysis and the $\mathrm{EC}_{50}$ was estimated using the $R$ language, version 2.6.2 for Mac OS X (R Development Core Team, 2008).

\section{Results}

\subsection{Reproduction}

All concentrations promoted a significant decrease of the offspring number $\left(F_{5,54}=103.3 ; p<0.001\right)$ (Fig. 1a). Furthermore, the highest concentration $\left(458.7 \mu \mathrm{g} \mathrm{L}^{-1}\right)$ promoted a total inhibition of reproduction process on maternal daphnids. Endosulfan sulphate increased a delay of first brood above the concentration of $45.8 \mu \mathrm{g} \mathrm{L}^{-1}$. Nevertheless, the survival of maternal daphnids was $100 \%$ for all concentrations tested. Neither dead offspring nor arrested eggs were observed during the test.

At the end of the test, daphnids were measured and their length was compared. All the concentrations promoted a significant decrease in the length of females $\left(F_{6,63}=97.8 ; p<0.001\right)$ (Fig. 1b). The pronounced decrease in adult size and a corresponding decrease in brood chamber size influenced the number of broods per daphnid. Consequently, D. magna exposed to endosulfan sulphate were smaller and released brood later than the control groups.

The moult of individual daphnids, exposed to all concentrations of endosulfan sulphate, was assessed daily. From the concentration of $45.8 \mu \mathrm{gl}^{-1}$ the moult frequency showed a significant decrease $\left(F_{6,63}=80.6 ; p<0.001\right)$ (Fig. 1c).

\subsection{Embryo toxicity}

Having established endosulfan sulphate effects in reproduction, growth and moulting of D. magna, we evaluated the implication of this compound in the embryo development of the crustacean. Embryo toxicity of endosulfan sulphate was evaluated 
a

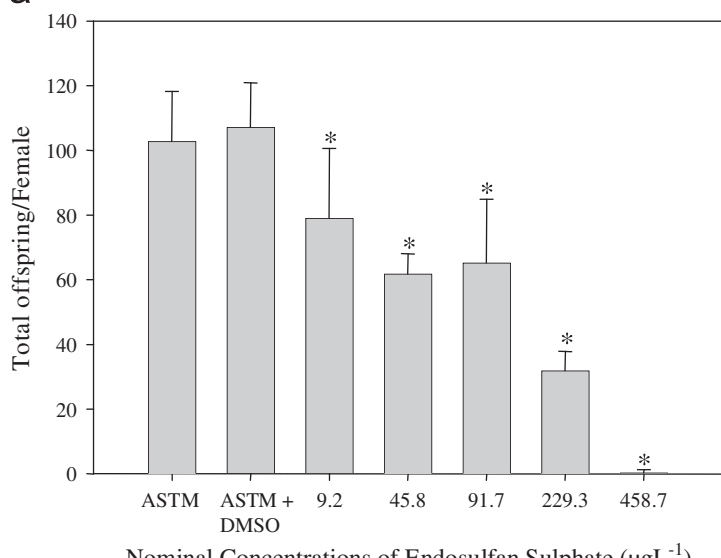

b

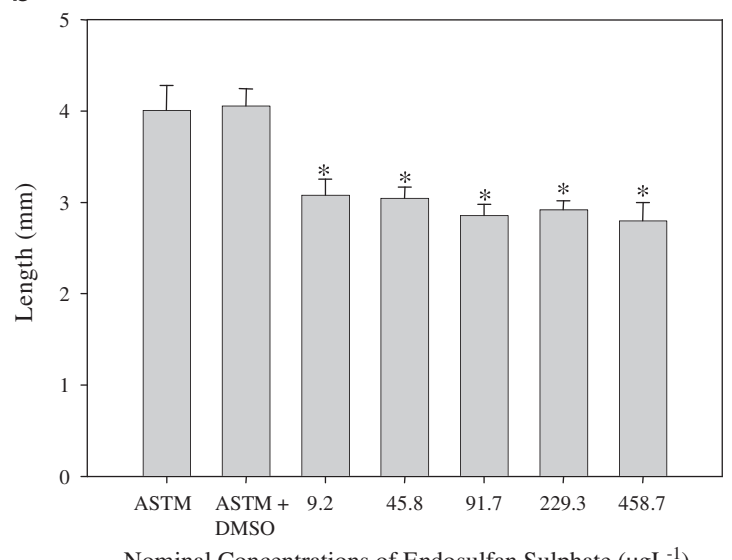

C

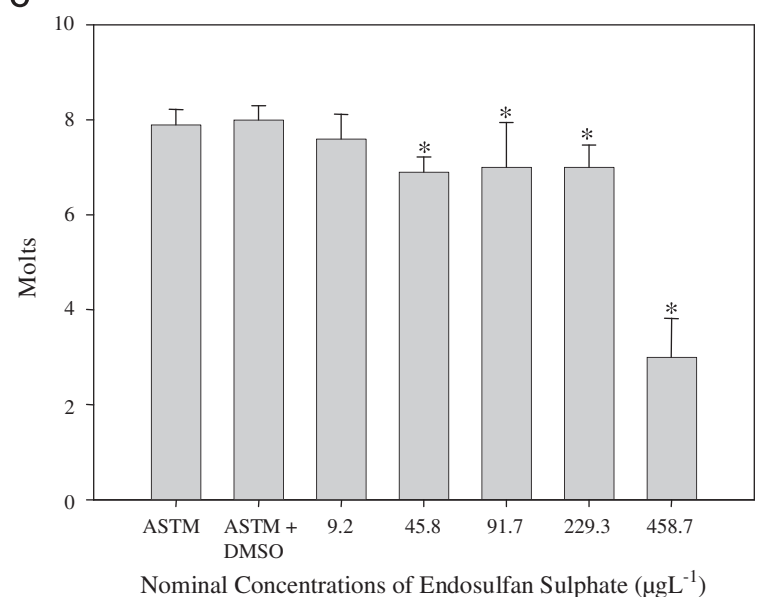

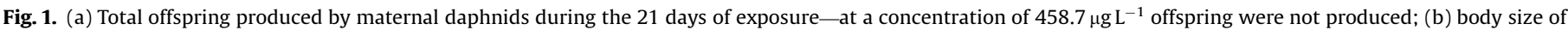

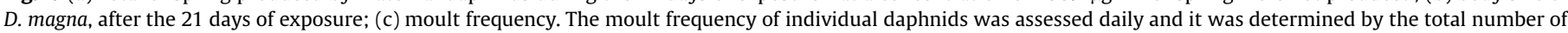

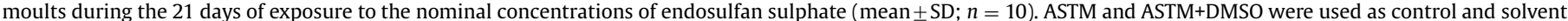
control, respectively. Asterisks indicate a significant difference from the control (Dunnett's test, $p<0.05$ ).

using two exposure designs: exposure of maternal daphnids (chronic bioassay) and the direct exposure of embryos to the compound. All concentrations promoted an increase in the development of abnormalities for both maternal exposure $\left(F_{5,54}=\right.$ $115.5 ; p<0.001)$ and direct embryo exposure $\left(F_{6,77}=46.7\right.$; $p<0.001$ ) (Fig. 2). Nevertheless, results showed a higher percentage of abnormalities in direct embryos exposure, compared to maternal exposure. Direct embryos exposure promoted the development of abnormalities between $75.0 \%$ and $100.0 \%$, for all concentrations.

Development effects induced by endosulfan sulphate through maternal exposure include underdeveloped second antennae, curved, incurved or inexistent shell spine and other morphological alterations of the carapace, without the appearance of arrested eggs (Fig. 3b-f). Direct embryo exposure to endosulfan sulphate promoted development effects, such as early development arrest, underdeveloped second antennae, curved, incurved or inexistent shell spine, and other morphological alterations of the carapace (Fig. 4b-d). The profile of the development abnormalities was different between the two bioassays. Hence, at maternal exposure endosulfan sulphate promoted mainly abnormalities at the curved shell spine and underdevelopment antennae, with a high incidence of abnormalities on shell spine (Fig. 5a). At direct embryo exposure, this compound caused curved shell spine and underdevelopment antennae at all concentrations, and from the

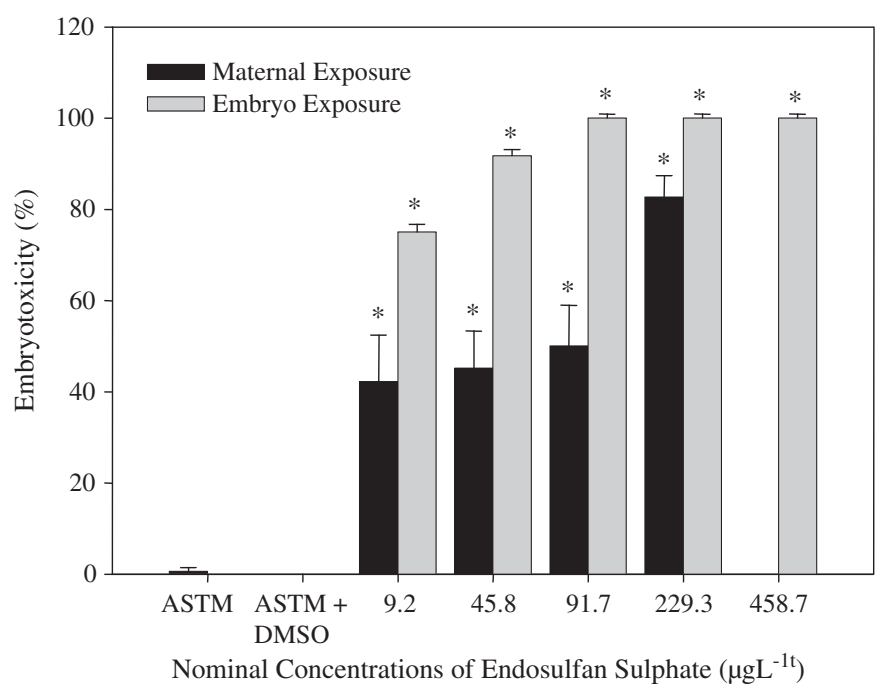

Fig. 2. Development abnormalities resulting from maternal exposure and embryo direct exposure to nominal concentrations of endosulfan sulphate (mean \pm SD; $n=12$ ). At maternal exposure concentration of $458.7 \mu \mathrm{g} \mathrm{L}^{-1}$ offspring were not produced. ASTM and ASTM+DMSO were used as control and solvent control, respectively. Asterisks indicate a significant difference from the control (Dunnett's test, $p<0.05$ ) 

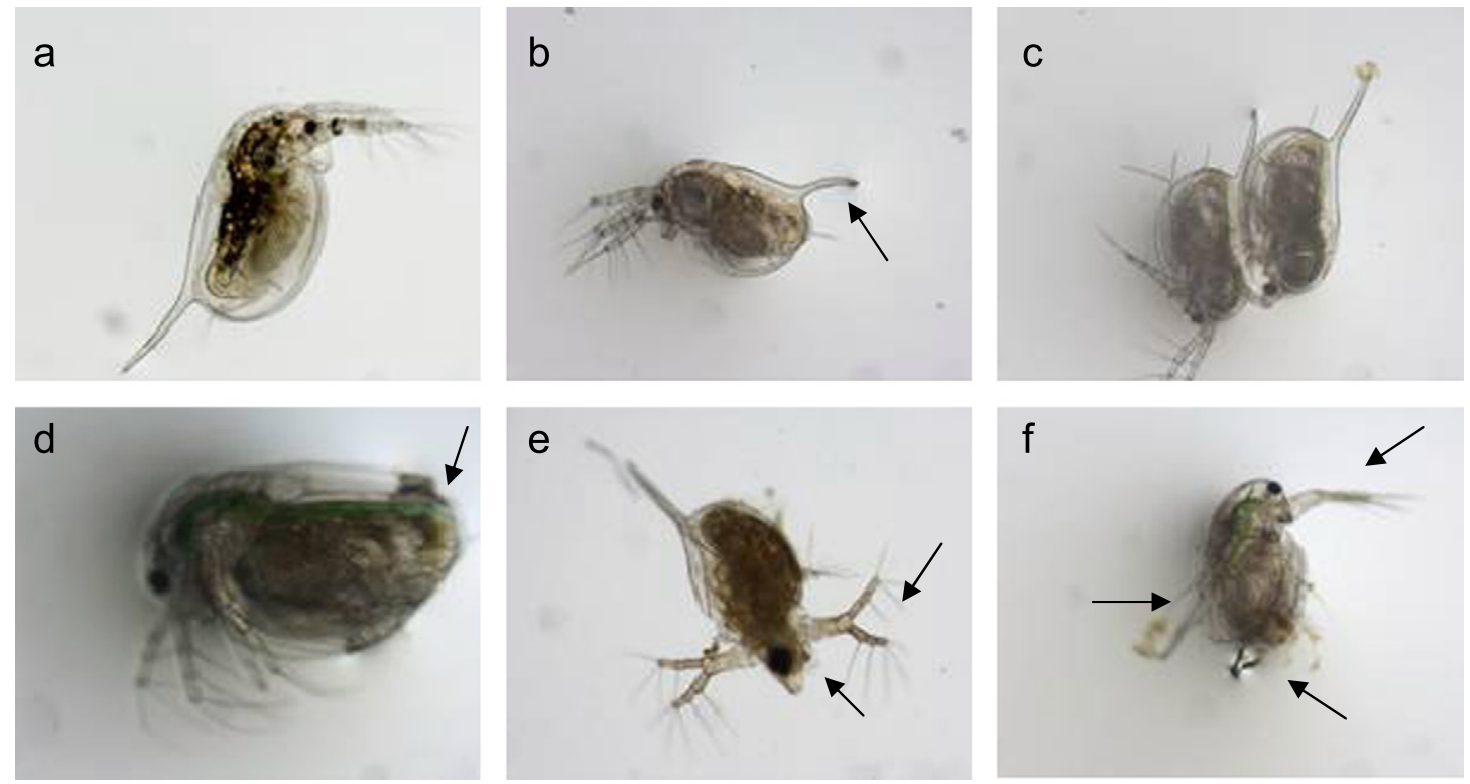

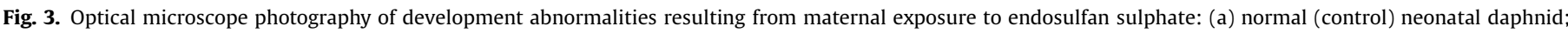

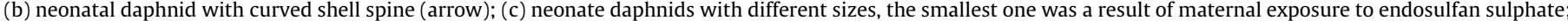

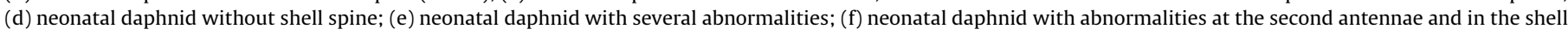
spine (arrow). All the neonatal daphnids with abnormalities (b-f) have the same age as the control (a).
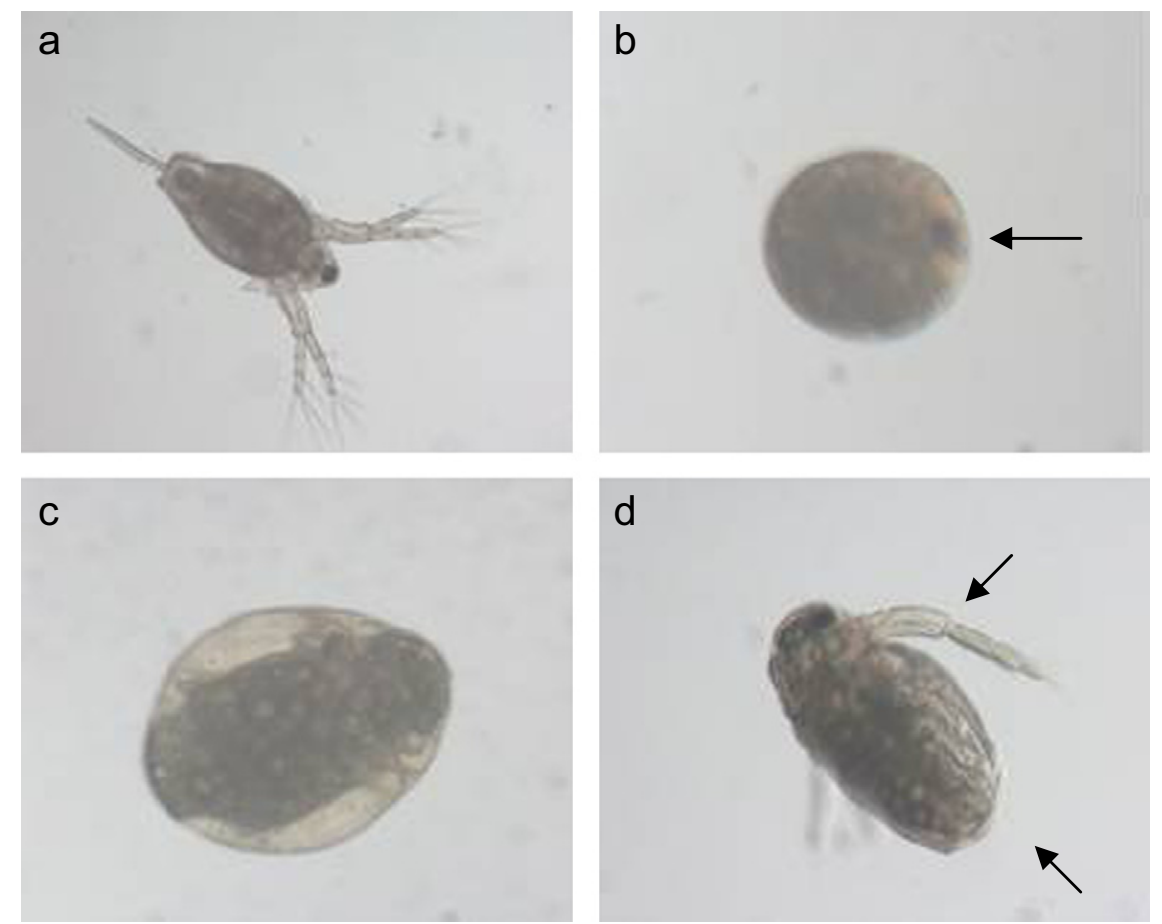

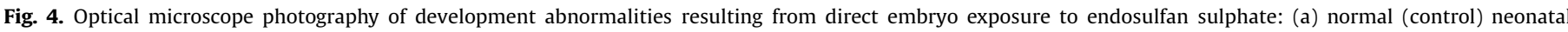

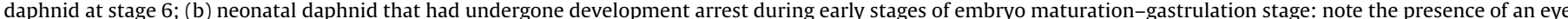

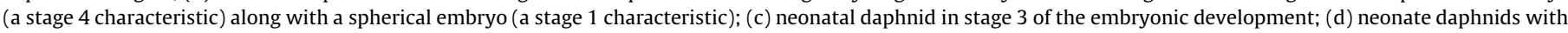

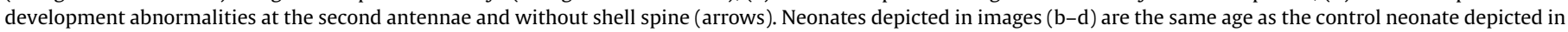
image (a).

concentration of $91.7 \mu \mathrm{g} \mathrm{L}^{-1}$ it promoted early development arrest (Fig. 5b).

\subsection{Sex determination}

Endosulfan sulphate reduced the total number of offspring for the range of concentrations investigated. The reduction of offspring number was attended with an increase of males daphnid production from the $91.7 \mu \mathrm{gl}^{-1}$ concentration (Table 1). Logistic regression on the data in the first assay yields a highly significant and positive slope $(p<0.001)$ and an estimated $\mathrm{EC}_{50}$ of $435.6 \pm 28.1 \mu \mathrm{g} \mathrm{L}^{-1}$. These values were confirmed by a second assay, also giving a positive slope $(p<0.001)$ and an estimated $\mathrm{EC}_{50}$ of $453.2 \pm 24 \mu \mathrm{g} \mathrm{L}^{-1}$. No male offspring was found in the control groups.

Please cite this article as: Palma, P., et al., Endosulfan sulphate interferes with reproduction, embryonic development and sex differentiation in Daphnia magna. Ecotoxicol. Environ. Saf. (2008), doi:10.1016/j.ecoenv.2008.04.018 
a

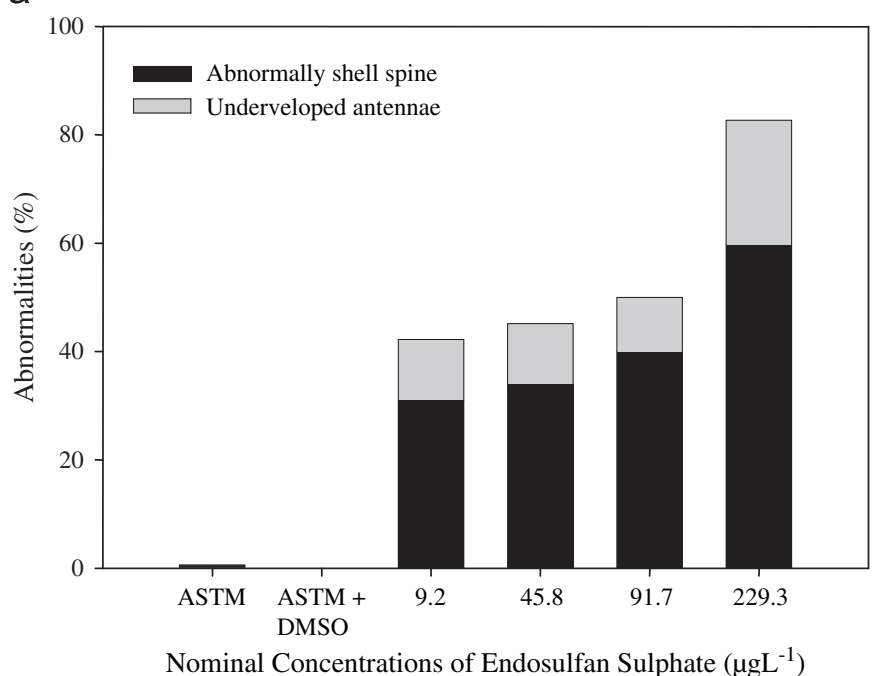

b

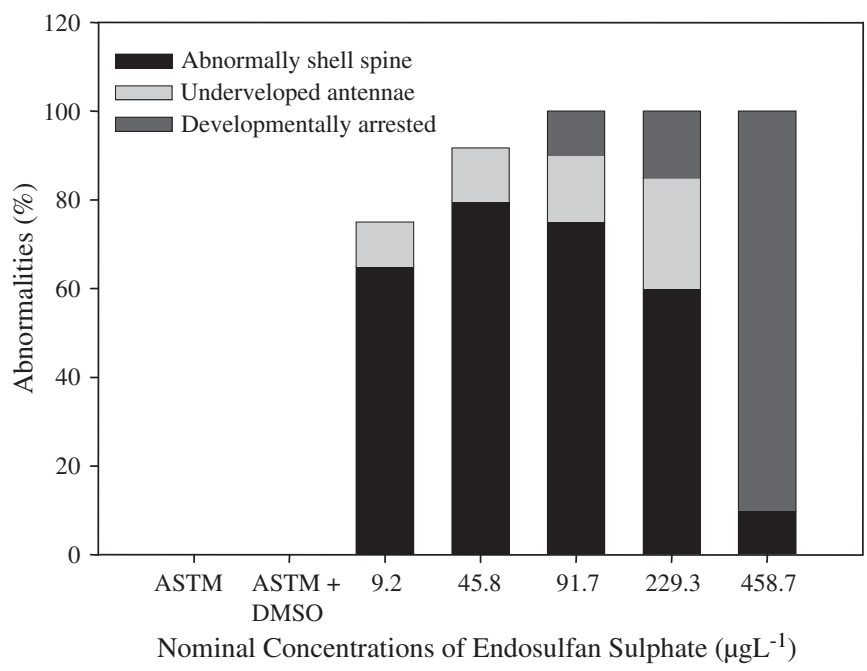

Fig. 5. Profile of developmental abnormalities resulting from the exposure of maternal daphnids (a) and embryos (b) to nominal concentrations of endosulfan sulphate (mean $\pm \mathrm{SD} ; n=12$ ). At maternal exposure concentration of $458.7 \mu \mathrm{g} \mathrm{l}^{-1}$ offspring were not produced. ASTM and ASTM+DMSO were used as control and solvent control, respectively. Asterisks indicate a significant difference from the control (Dunnett's test, $p<0.05$ ).

\section{Discussion}

The purpose of this study was to assess the sublethal effects promoted by endosulfan sulphate in life cycle, embryo toxicity and sex differentiation of the crustacean D. magna.

Concerning the reproduction rate, the results demonstrate that endosulfan sulphate promotes the decrease of offspring number from the concentration of $9.20 \mu \mathrm{g} \mathrm{L}^{-1}$. The reduction of the reproduction rate was not attended by an increase in mortality. There were no data about the chronic effects of endosulfan sulphate on reproduction. However, several reports exist about endosulfan; thus Sunderam et al. (1994) reported a decrease of reproduction at an endosulfan concentration of $20.0 \mu \mathrm{g} \mathrm{L}^{-1}$ for Ceriodaphnia of dubai. Results in D. magna showed an effect on reproductive output at about $120.0 \mu \mathrm{g} \mathrm{L}^{-1}$ of endosulfan (Fernandez-Casalderrey et al., 1993). Barry et al. (1995) indicated that endosulfan promoted a decrease in the fecundity of D. carinata at a concentration of $320.0 \mu \mathrm{gl}^{-1}$. Hence, according to the results and despite endosulfan and endosulfan sulphate having a similar acute toxicity, at chronic exposition the toxicity promoted by endosulfan sulphate occurs at concentrations below the ones accounted for endosulfan.

The decrease of offspring number is followed by a diminution of maternal daphnids size. Studies showed that the decrease in the number of offspring may be influenced by the size of maternal daphnids, which leads to the decrease of brood chamber and, consequently, limits the accommodation of the eggs (LeBlanc and McLachlan, 1999). The results suggest that this mechanism is not the only one responsible for the reduction of offspring number induced by endosulfan sulphate as from the concentration of $91.7 \mu \mathrm{g} \mathrm{L}^{-1}$ there is no decrease of maternal daphnids size, compared to the other concentrations. But, on the other hand, the decrease of offspring persisted; the changes in the growth process are not described for endosulfan.

The changes in growth and offspring production were followed by the reduction in moulting frequency. The number of moults, during the time of exposition, is influenced by the increment of endosulfan sulphate concentration. Further, at the highest concentration $\left(458.7 \mu \mathrm{g} \mathrm{L}^{-1}\right)$, there is a strong reduction of moulting frequency followed by a total inhibition of reproduction process. Thus, endosulfan sulphate also acts on the moulting process such as its precursor endosulfan (Zou and Fingerman, 1997). Nevertheless, the concentrations of endosulfan sulphate, which affected the moulting process, are much lower than that of endosulfan (Zou and Fingerman, 1997).

The reduction in moulting frequency and size does not show a statistical correlation (Pearson correlation; $r=0.471 ; n=70$; $p>0.05)$. This fact is in accordance with what has been described for other compounds that act on moulting and growth process, such as cyproterone acetate (LeBlanc and McLachlan, 1999), testosterone (Mu and LeBlanc, 2002a) and fenarimol (Mu and LeBlanc, 2002b). Our results may be sustained by data that indicate that growth and moulting are highly correlated (Chang and O'Connor, 1988), although both are independently regulated (LeBlanc and McLachlan, 1999).

Having determined the endosulfan sulphate effects in reproduction, growth and moulting, we subsequently analysed the implication of this compound for embryonic development. According to our results, endosulfan sulphate is toxic to daphnid embryos. Embryo toxicity is the combined result of both direct embryo exposure and maternal exposure to endosulfan sulphate.

However, the embryo-toxic effects are more pronounced during direct embryo exposure, and they occur in both stages of embryonic development, gastrulation (stage 2) and organogenesis (stage 3-6). Above concentrations of $91.7 \mu \mathrm{g} \mathrm{L}^{-1}$, the results show that endosulfan sulphate acts in the initial stages of embryonic development and that, at the highest concentration, $90.0 \%$ of the eggs are at the gastrulation stage.

Our results show that the embryo toxicity promoted by endosulfan sulphate through maternal exposure has no effect on gastrulation, but interferes with the normal organogenesis of embryos. Hence, the profile of development abnormalities is different in two exposures designs, which may suggest that endosulfan sulphate is directly embryo toxic to daphnids and that the maternal organism is not the only vector for the exposition of endosulfan sulphate to daphnids embryos. The embryo toxicity induced by this compound through maternal exposure may be a result of its toxicity to the mother, or of the maternal biotransformation of endosulfan sulphate to an embryo-toxic derivate, as it was described for the fungicide propiconazole (Kast-Hutcheson et al., 2001).

The increase of abnormalities in embryonic development may be related to the decrease of the levels of ecdysteroids in embryos, as ecdysteroids are critical to normal embryonic development (Mu and LeBlanc, 2002a, b, 2004). The chronic toxic effects 
Table 1

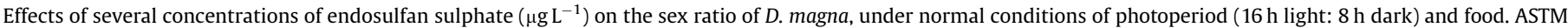

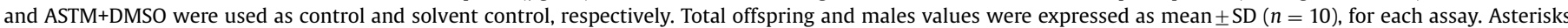
indicate that the regression coefficients for slopes, obtained by logistic regression analysis, were statistically significant $(p<0.001)$

\begin{tabular}{|c|c|c|c|c|c|c|c|c|}
\hline & \multicolumn{8}{|c|}{ Endosulfan sulphate $\left(\mu \mathrm{g} \mathrm{L}^{-1}\right)$} \\
\hline & \multicolumn{4}{|l|}{ Assay 1} & \multicolumn{4}{|l|}{ Assay 2} \\
\hline & Total offspring & Males & Sex ratio & $\begin{array}{l}\text { Broods containing } \\
\text { male offspring (\%) }\end{array}$ & Total offspring & Males & Sex ratio & $\begin{array}{l}\text { Broods containing } \\
\text { male offspring (\%) }\end{array}$ \\
\hline ASTM & $102.8 \pm 9.9$ & 0 & 0 & 0 & $112.6 \pm 7.4$ & 0 & 0 & 0 \\
\hline ASTM+DMSO & $107.1 \pm 13.8$ & 0 & 0 & 0 & $107.1 \pm 10.5$ & 0 & 0 & 0 \\
\hline 9.17 & $79.1 \pm 21.5$ & 0 & 0 & 0 & $83.2 \pm 15.8$ & 0 & 0 & 0 \\
\hline 45.8 & $61.8 \pm 6.3$ & 0 & 0 & 0 & $66.8 \pm 6.5$ & 0 & 0 & 0 \\
\hline 91.7 & $65.2 \pm 15.9$ & $1.2 \pm 0.8$ & $0.018^{*}$ & 50 & $32.8 \pm 3.5$ & $0.6 \pm 0.5$ & $0.018^{*}$ & 50 \\
\hline 229.3 & $31.8 \pm 6.0$ & $1.3 \pm 0.6$ & $0.041^{*}$ & 100 & $25.1 \pm 6.1$ & $1.8 \pm 0.4$ & $0.071^{*}$ & 100 \\
\hline 458.7 & - & - & n.d. & - & $3.9 \pm 1.8$ & $1.9 \pm 0.3$ & $0.487^{*}$ & 100 \\
\hline
\end{tabular}

n.d. (not determined)—offspring were not produced at this concentration.

promoted by endosulfan sulphate on moulting frequency, growth, offspring number and embryonic development are similar to those that are reported for compounds with antiecdysteroid activity, such as diethylstilbestrol (Chang, 1993), testosterone (LeBlanc et al., 2000; Mu and LeBlanc, 2002b) and fenarimol (Mu and LeBlanc, 2002b). Therefore, we suggest that endosulfan sulphate interferes with the ecdysteroids activity of the crustacean D. magna.

Sex determination of daphnids takes place during a critical period of about $1 \mathrm{~h}$ before egg deposition in the brood chamber (Zou and Fingerman, 2003). Eggs produced by parthenogenesis will be differentiated, either in females or in males, depending on the environmental conditions (Rodríguez et al., 2007). On D. magna the sex of neonates was determined as an indicator of endocrine disruption (Tatarazako et al., 2003; Oda et al., 2005). The induction of male offspring in D. magna has proved to be a highly specific endpoint for the detection of juvenile hormone analogues (Tatarazako and Oda, 2007).

The evaluation of sex determination endpoint was performed without previous stimulation of male production. This fact allows excluding possible synergistic or antagonistic chemical effects with environmental change, which is, by itself, the main cause of male production (Tatarazako et al., 2003). The results show an increase in sex ratio of $D$. magna followed by endosulfan sulphate exposure from 91.7 to $458.7 \mu \mathrm{g} \mathrm{L}^{-1}$, which suggests that endosulfan sulphate interferes with the sex differentiation of this aquatic invertebrate species. Some studies indicate that endosulfan does not act in the sex differentiation of crustacean D. magna (Zou and Fingerman, 1997; Merrit et al., 1999), which may denote that endosulfan sulphate has a distinct mode of action on some process of daphnids life cycle than its precursor.

The concentrations of endosulfan sulphate in surface waters range from 0.01 to $1.80 \mu \mathrm{g} \mathrm{L}^{-1}$, which were approximately 5.5 times lower than the concentrations that promoted chronic toxic effects (Cerejeira et al., 2003; Leong et al., 2007; Palma et al., 2007, submitted). This fact may indicate that no ecologic hazard exists for the invertebrate species of aquatic ecosystems. However, this compound has a considerable bioaccumulation with high bioconcentration factors. The bioconcentration factor for $D$. magna was 3.278 (DeLorenzo et al., 2002). For yellow tetra fish Hyphassobrycon bifascitus the bioconcentration factor was 6000 (Jonsson and Toledo, 1993). Nowak et al. (1995) reported a concentration of endosulfan metabolites of $23.5 \mu \mathrm{g} \mathrm{kg}^{-1}$ (wet weight) in carp Cyprinus carpio. Further studies are necessary to define the specific mechanism responsible for the toxic effects of this compound. Such studies may provide information on the specific and inherent toxicity of the compound and the understanding of endosulfan sulphate toxicological profile on aquatic invertebrate species.

\section{Conclusions}

Results from this study indicate that endosulfan sulphate acts on the reproduction rate of daphnids by decreasing the offspring number, growth and moulting frequency. This decrease is attended by the increment of development abnormalities in a concentration-dependent form. The sublethal toxicological effects of endosulfan sulphate are similar to other compounds that have antiecdysteroid activity. Thus, the antiecdysteroid activity of endosulfan sulphate deserves more investigation and may be one of the reasons for the toxic effects observed in crustacean life cycle studies. The relationship between the possible anti-ecdysteroidal activity of this compound and its effect on the production of male offspring remains to be established.

The endosulfan sulphate concentrations, which promote chronic effects in D. magna life cycle, are below those of its precursor endosulfan. Furthermore, the reduction in the growth and appearance of daphnid males has not been reported for endosulfan. Considering these facts we suggest that endosulfan sulphate has a greater ecological impact on aquatic invertebrate species than its precursor.

Results of this investigation provide evidence that ecotoxicological testing, covering the entire life cycle of test animals, can be a useful tool for determining the mechanism of action, by which pollutants promote changes in D. magna population, as well as for the estimation of safe environmental concentration of contaminants.

\section{Declaration}

All the authors declare that any studies involving humans or experimental animals were conducted in accordance with national and institutional guidelines for the protection of human subjects and animals welfare.

Information about the funding sources received to support the work

This work was financially supported by the "Programa Operacional Ciência e Inovação 2010" through the Project GG/ GGP/ME621-0167/05, with partial funding from the FEDER. The authors would like to thank Andreas Bohn for his support in statistical questions. 


\section{References}

ASTM, 1998. Standard practice for conducting toxicity tests with fishes, microinvertebrates and amphibians. E729-90. In: Annual Book of ASTM Standards. American Society of Testing Materials, Philadelphia, pp. 271-296.

Baird, D.J., Barber, I., Bradley, M., Calow, P., Soares, A.M.V.M., 1989. The Daphnia bioassay: a critique. Hydrobiologia 188-189, 403-406.

Barbosa, I.A., Martins, R.M., Sáe Melo, M.L., Soares, A.M.V.M., 2003. Acute and chronic toxicity of dimethylsulfoxide to Daphnia magna. Bull. Environ. Contam. Toxicol. 70, 1264-1268.

Barry, M.J., Logan, D.C., Ahokas, J.T., Holdway, D.A., 1995. Effect of algal food concentration on toxicity of two agricultural pesticides to Daphnia carinata. Ecotoxicol. Environ. Saf. 32, 273-279.

Cerejeira, M.J., Viana, P., Batista, S., Pereira, T., Silva, E., Valério, M.J., Silva, A., Ferreira, M., Silva-Fernandes, A.M., 2003. Pesticides in Portugal surface and ground waters. Water Res. 37, 1055-1063.

Chang, E.S., 1993. Comparative endocrinology of moulting and reproduction: insects and crustaceans. Annu. Rev. Entomol. 38, 161-180.

Chang, E.S., O'Connor, D., 1988. Crustacea. Moulting. In: Laufer, H., Downer, G.H (Eds.), Endocrinology of Selected Invertebrate Types. Alan R. Liss, New York, USA, pp. 259-278

DeFur, P.L., 2004. Use and role of invertebrate models in endocrine disruptor research and testing. ILAR J. 45 (4), 484-493.

DeLorenzo, M.E., Taylor, L.A., Lund, S.A., Pennington, P.L., Strozier, E.D., Fulton, M.H., 2002. Toxicity and bioconcentration potential of the agricultural pesticide endosulfan in phytoplakton and zooplankton. Arch. Environ. Contam. Toxicol. $42,173-181$.

Fernandez-Casalderrey, A., Ferrando, M.D., Andrey-Moliner, E., 1993. Effects of endosulfan on survival, growth and reproduction of D. magna. Comp. Biochem. Physiol. 106, 437-441.

Foersom, L.L., DeFur, P.L. Tuberty, S., 2001. Effects of endosulfan on moulting in juvenile red swamp crayfish, Procambarus clarki. In: Annual Meeting of the Society of Environmental Toxicology and Chemistry. SETAC Press, Baltimore, MD, Pensacola, FL.

Herrmann, M., 2003. Endosulfan preliminary dossier. In: Proceedings, fourth Meeting of the United Nations Economic Commission for Europe Expert group on Persistent Organic Pollutants. Oslo, Norway, pp. 59-61.

Jonsson, C.M., Toledo, C.F., 1993. Bioaccumulation and elimination of endosulfan in the fish yellow tetra (Hyphassobrycon bifascitus). Bull. Environ. Contam. Toxicol. 50 (4), 572-577.

Kast-Hutcheson, K., Rider, C.V., LeBlanc, G.A., 2001. The fungicide propiconazole interferes with embryonic development of the crustacean Daphnia magna. Environ.Toxicol. 20, 502-509.

Klaassen, C.D., 2001. Cassaret \& Doull's Toxicology: The Basic Science of Poisons, sixth ed. McGraw-Hill, USA.

LeBlanc, G.A., McLachlan, J.B., 1999. Moult-independent growth of Daphnia magna by vertebrate antiandrogen. Environ. Toxicol. Chem. 7, 1450-1455.

LeBlanc, G.A., Bain, L.J., Wilson, V.S., 1997. Pesticides: multiple mechanisms of desmasculinization. Mol. Cel. Endocrinol. 126, 1-5.

LeBlanc, G.A., Xueyan, M., Rider, C.V., 2000. Embryotoxicity of the alkylphenol degradation product 4-nonylphenol to the crustacean Daphnia magna. Enviro. Health Perspect. 108, 1133-1138.

Lemke, A.E., 1980. Comprehensive report. Interlaboratory comparison of acute testing set. In: Ambient Water Quality for Endosulfan. USEPA, Environmenta Research Laboratory, Duluth, Minnesota, Washington, DC.

Leong, K.H., Benjamin Tan, L.L., Mustafa, A.M., 2007. Contamination levels of selected organochlorine and organophosphate pesticides in the Selangor River, Malaysia between 2002 and 2003. Chemosphere 66, 1153-1159.

McKinlay, R., Plant, J.A., Bell, J.N.B., Voulvoulis, N., 2007. Endocrine disrupting pesticides: implications for risk assessment. Environ. Int. 34 (2), 170-172

Merrit, C.M., Torrentera, L., Winter, K.M., Tornehl, C.K., Girvin, K., Dodson, S., 1999. Dieldrin reduces male production and sex ratio in Daphnia galeata mendotae. Toxicol. Ind. Health 15, 193-200.
Mu, X., LeBlanc, G.A., 2002a. Development toxicity of testosterone in the crustacean Daphnia magna involves antiecdysteroidal activity. Gen. Comp. Endocrinol. 129, 127-133.

Mu, X., LeBlanc, G.A., 2002b. Environmental antiecdysteroids alter embryo development in the crustacean Daphnia magna. J. Exp. Zool. 292, 287-292.

$\mathrm{Mu}$, X., LeBlanc, G.A., 2004. Synergistic interaction of endocrine disrupting chemicals: model development using an ecdysone receptor antagonist and a hormone synthesis inhibitor. Environ. Toxicol. Chem. 23, 1085-1091.

Nowak, B., Goodsell, A., Julli, M., 1995. Residues of endosulfan in carp as an indicator of exposure conditions. Ecotoxicology 4, 363-371.

OCDE (Organization for Economic Cooperation and Development), 1998. OCDE 211, Daphnia magna reproduction test. Paris.

Oda, S., Tatarazako, N., Watanabe, H., Morita, M., Iguchi, T., 2005. Production of male neonates in Dapnhia magna (Cladocera, Crustacea) exposed to juvenile hormones and their analogs. Chemosphere 61, 1168-1174.

Olmstead, A.W., LeBlanc, G.A., 2000. Effects of endocrine-active chemicals on the development of sex characteristics of Daphnia magna. Environ. Toxicol. Chem. 8, 2107-2113.

Pfeuffer, R.J., Rand, G.M., 2004. South Florida ambient pesticides monitoring program. Ecotoxicology 13, 195-205.

R Development Core Team, 2008. R: A Language and Environment for Statistical Computing. R Foundation for Statistical Computing, Vienna, Austria URL $\langle$ http://www.R-project.org $\rangle$.

Rodríguez, E.M., Medesani, D.A., Fingerman, M., 2007. Endocrine disruption in crustaceans due to pollutants: a review. Comp. Biochem. Physiol, Part A 146, 661-671.

Shivaramaiah, H.M., Sanchez-Bayo, F., Al-Rifai, J., Kennedy, I.R., 2005. The fate of endosulfan in water. J. Environ. Sci. Health Part B 40, 711-720.

Sobral, O., Chastinet, C., Nogueira, A., Soares, A.M.V.M., Gonçalves, F., Ribeiro, R., 2001. In vitro development of parthenogenetic eggs: a fast ecotoxicity test with Daphnia magna. Ecotoxicol. Environ. Saf. 50, 174-179.

Sokal, R.R., Rohlf, F.J., 1995. Biometry-The Principles and Practice of Statistics in Biological Research, third ed. W.H. Freeman and Company, New York.

Soto, A.M., Sonnenschein, C., Chung, K.L., Fernandez, M.F., Olea, N., Serrano, F.O. 1995. The E-SCREEN assay as a tool to identify estrogens: an update on estrogenic environmental pollutants. Environ. Health Perspect. 103 (7), $113-122$.

STATISTICA (data analysis software system), 2001. Version 6. Statsoft, Inc. $\langle$ www.statsoft.com $\rangle$.

Sunderam, R.I.M., Thompson, G.B., Chapman, J.C., Cheng, D.M.H., 1994. Acute and chronic toxicity of endosulfan to two Australian cladocerans and their applicability in deriving water quality criteria. Arch. Environ. Contam. Toxicol. 27, 541-545

Tatarazako, N., Oda, S., 2007. The water flea Daphnia magna (Crustacea, Cladocera) as a test species for screening and evaluation of chemicals with endocrine disrupting effects on crustaceans. Ecotoxicology 16, 197-203.

Tatarazako, N., Oda, S., Watanabe, H., Morita, M., Iguchi, T., 2003. Juvenile hormone agonists affect the occurrence of male Daphnia. Chemosphere 53 (8), 827-833.

Wan, M.T., Kuo, J., Buday, C., Schroeder, G., Van Aggelen, G., Pasternak, J., 2004. Toxicity of $\alpha-, \beta-,(\alpha+\beta)$-endosulfan and their formulated and degradation products to Daphnia magna, Hyalella azteca, Oncorhynchus mykiss, Oncorhynchus kisutch, and biological implications in streams. Environ. Toxicol. Chem. 24 (5), 1146-1154

Wirth, E.F., Lund, S.A., Fulton, M.H., Scott, G.I., 2001. Determination of acute mortality in adults and sublethal embryo responses of Palaemonetes pugio to endosulfan and methoprene exposure. Aquat. Toxicol. 53, 9-18.

Zar, J.H., 1996. Biostatistical Analysis, third ed. Prentice-Hall International, Englewood Cliffs, NJ, USA

Zou, E., Fingerman, M., 1997. Synthetic estrogenic agents do not interfere with sex differention but do inhibit moulting of the cladoceran Daphnia magna. Bull. Environ. Contam. Toxicol. 58, 596-602.

Zou, E., Fingerman, M., 2003. Endocrine disruption of sexual development, reproduction and growth by environmental organic contaminants: current perspectives. Curr. Top. Pharmacol. 7, 69-80. 